International Journal of Environmental Research and

Public Health

ISSN 1660-4601

www.mdpi.com/journal/ijerph

Article

\title{
Concentration of Lead, Mercury, Cadmium, Aluminum, Arsenic and Manganese in Umbilical Cord Blood of Jamaican Newborns
}

\author{
Mohammad H. Rahbar ${ }^{1,2,3, *}$, Maureen Samms-Vaughan ${ }^{4}$, Aisha S. Dickerson ${ }^{3}$, \\ Manouchehr Hessabi ${ }^{3}$, Jan Bressler ${ }^{5}$, Charlene Coore Desai ${ }^{4}$, \\ Sydonnie Shakespeare-Pellington ${ }^{4}$, Jody-Ann Reece ${ }^{4}$, Renee Morgan ${ }^{4}$, \\ Katherine A. Loveland ${ }^{6}$, Megan L. Grove ${ }^{5}$ and Eric Boerwinkle ${ }^{1,5}$ \\ 1 Division of Epidemiology, Human Genetics, and Environmental Sciences (EHGES), \\ University of Texas School of Public Health at Houston, Houston, TX 77030, USA; \\ E-Mail: eric.boerwinkle@uth.tmc.edu
}

2 Division of Clinical and Translational Sciences, Department of Internal Medicine, University of Texas Medical School at Houston, Houston, TX 77030, USA

3 Biostatistics/Epidemiology/Research Design (BERD) Component, Center for Clinical and Translational Sciences (CCTS), University of Texas Health Science Center at Houston, Houston, TX 77030, USA; E-Mails: aisha.s.dickerson@uth.tmc.edu (A.S.D.); manouchehr.hessabi@uth.tmc.edu (M.H.)

4 Department of Child \& Adolescent Health, The University of the West Indies (UWI), Mona Campus, Kingston 7, Jamaica; E-Mails: msammsvaughan@gmail.com (M.S.-V.); cooredesai@googlemail.com (C.C.D.); sydonniesp@gmail.com (S.S.-P.); jodyreece@yahoo.com (J.-A.R.); renee.n.morgan@gmail.com (R.M.)

5 Human Genetics Center, University of Texas School of Public Health at Houston, Houston, TX 77030, USA; E-Mails: jan.bressler@uth.tmc.edu (J.B.); megan.1.grove@uth.tmc.edu (M.L.G.)

6 Department of Psychiatry and Behavioral Sciences, University of Texas Medical School at Houston, Houston, TX 77054, USA; E-Mail: katherine.a.loveland@uth.tmc.edu

* Author to whom correspondence should be addressed; E-Mail: Mohammad.H.Rahbar@uth.tmc.edu; Tel.: +1-713-500-7901; Fax: +1-713-500-0766.

Academic Editor: Paul B. Tchounwou

Received: 15 February 2015 / Accepted: 17 April 2015 / Published: 23 April 2015 


\begin{abstract}
The objective of this study was to characterize the concentrations of lead, mercury, cadmium, aluminum, and manganese in umbilical cord blood of Jamaican newborns and to explore the possible association between concentrations of these elements and certain birth outcomes. Based on data from 100 pregnant mothers and their 100 newborns who were enrolled from Jamaica in 2011, the arithmetic mean (standard deviation) concentrations of cord blood lead, mercury, aluminum, and manganese were 0.8 $(1.3 \mu \mathrm{g} / \mathrm{dL}), 4.4(2.4 \mu \mathrm{g} / \mathrm{L}), 10.9(9.2 \mu \mathrm{g} / \mathrm{L})$, and $43.7(17.7 \mu \mathrm{g} / \mathrm{L})$, respectively. In univariable General Linear Models, the geometric mean cord blood aluminum concentration was higher for children whose mothers had completed their education up to high school compared to those whose mothers had any education beyond high school (12.2 $\mu \mathrm{g} / \mathrm{L} v s .6 .4 \mu \mathrm{g} / \mathrm{L} ; p<0.01)$. After controlling for maternal education level and socioeconomic status (through ownership of a family car), the cord blood lead concentration was significantly associated with head circumference (adjusted $p<0.01$ ). Our results not only provide levels of arsenic and the aforementioned metals in cord blood that could serve as a reference for the Jamaican population, but also replicate previously reported significant associations between cord blood lead concentrations and head circumference at birth in other populations.
\end{abstract}

Keywords: lead; mercury; aluminum; arsenic; cadmium; manganese; cord blood; newborns; Jamaica

\title{
1. Introduction
}

Exposure to several trace elements/heavy metals, including lead, mercury, cadmium, arsenic, and aluminum during pregnancy has been shown to be harmful to the developing fetus [1-9] and can be harmful to the human nervous system, even at low levels of exposure [10-13]. The adverse effects of lead exposure during pregnancy on birth outcomes have been well documented, including lower birth weight [14], lower birth crown-heel length and head circumference [15-17], and preterm birth [18,19]. Also, several studies have reported that methyl mercury could easily cross the placenta and affect cognitive development [3,4,20-22]. Although the placenta acts as a barrier, protecting the fetus from cadmium exposure by increasing metallothionein expression [23], the presence of cadmium in cord blood has been associated with decreased birth weight [24] and increased incidence of preterm delivery [25].

Sources of exposure to lead include leaded gasoline, leaded paint, dust and soil contaminated with lead, water carried in lead pipes, industrial emissions or occupational exposures [26]. Exposure to mercury mainly occurs through ingestion of contaminated fish (methyl mercury) [27] or dental amalgams (inorganic mercury) [28]. Environmental cadmium pollution is ubiquitous owing to industrial activities, use of phosphate fertilizers, combustion of motor fuels in vehicles and particles released by tire wear, all of which result in emissions to air, soil and water [29-31]. Although smoking tobacco is the most important source of exposure to cadmium, in nonsmokers diet is considered as the most important source of cadmium exposure [32]. A study that investigated the role of air pollutants in birth outcomes has reported statistically significant associations between low birth weight and levels of 
aluminum (in all trimesters), calcium, nickel, silicon, and zinc (in the third trimester), as well as elemental carbon and titanium (in the first trimester) [33,34]. Shi et al. reported preterm birth has a stronger spatial association with groundwater arsenic than term low birth weight in New Hampshire, USA [35]. Manganese is an essential mineral nutrient that plays an important role in fetal development and in other important aspects of metabolism. However, elevated manganese can have potential neurotoxic effects, particularly in infants. Limited information is available regarding the effects of elevated manganese in the development of the human fetus. The findings from a relatively recent study indicate that lower maternal blood manganese is associated with fetal intrauterine growth retardation and lower birth weight [36]. Although, a study based on a cohort of 470 mother-infant pairs from Oklahoma did not find a significant linear association between umbilical cord blood manganese and infant birth weight, they did find a non-linear relationship between maternal blood manganese and infant birth weight [37].

Previous studies have reported a high level of several trace elements and heavy metals in the soil of Jamaica [38] including lead [38,39], aluminum [38,40], arsenic [38], and cadmium [41,42]. Wright et al. investigated concentrations of nine residual metals (chromium, manganese, nickel, copper, zinc, arsenic, cadmium, lead, and mercury) in some Jamaican foods and reported a significant correlation $(r \geq 0.7)$ between levels of lead in soil and agricultural produce [43]. However, Howe et al. conducted a similar study in Jamaica and reported that lead absorbed by vegetables did not pose a significant risk of elevated blood lead concentrations in the Jamaican population [44]. Recent reports indicate that the arithmetic mean blood arsenic concentration of Jamaican children is $4.55 \mu \mathrm{g} / \mathrm{L}$ [45] and is about 4.5 times the blood arsenic concentration for unexposed individuals in the US [46]. Similar reports from our research in Jamaica also indicate that the arithmetic mean blood cadmium concentration is relatively low, $0.16 \mu \mathrm{g} / \mathrm{L}$ [47], and that the arithmetic mean blood manganese concentration $(10.9 \mu \mathrm{g} / \mathrm{L})[48]$ and the arithmetic mean blood mercury concentration $(1.16 \mu \mathrm{g} / \mathrm{L})$, are the same as or more than three times higher than that of children from the US, respectively [49].

In this study, concentrations of the aforementioned trace elements/heavy metals in umbilical cord blood of Jamaican newborns were determined and factors associated with levels of these toxins were identified. In addition, possible relationships between cord blood metals and certain birth outcomes including birth weight, crown-heel length, and head circumference were explored.

\section{Materials and Methods}

\subsection{General Description}

Data for this study were generated in collaboration with faculty at the University of the West Indies (UWI), Mona Campus, Kingston, Jamaica. The JA Kids study, a birth cohort study in Jamaica, enrolled mothers between the third trimester and delivery in 2011 [50-53]. The participants in the study reported here comprise a subsample of 100 mothers with 100 newborns from whom cord blood was isolated. To the extent possible, data from two questionnaires administered to mothers in their third trimester and at the time of delivery by the JA Kids study were linked with concentrations of the aforementioned trace elements/metals. Through these two questionnaires, demographic and socioeconomic information, including level of maternal education, and certain assets owned by the 
family were collected. The mean age of mothers at delivery was 29.6 years. Fifty-five percent of the newborns were female. Sixty percent of mothers reported previous pregnancies. Information regarding other socio-demographic and socio-economic characteristics of the study population is provided in Table 1.

Study data were collected and managed using REDCap electronic data capture tools hosted at the University of Texas Health Science Center at Houston [54]. Also, $2 \mathrm{~mL}$ of cord blood were collected into plastic tubes containing EDTA which were prescreened for several trace elements or metals, including lead, mercury, arsenic, cadmium, manganese, and aluminum [55-57]. The blood samples were frozen and stored at $-20{ }^{\circ} \mathrm{C}$ until they were transported to the Michigan Department of Community Health (MDCH) Trace Metals Lab at ambient temperature on ice packs for trace metal analyses. Institutional Review Boards (IRBs) of the University of Texas Health Science Center at Houston and UWI approved this study. All participating mothers provided written informed consent, in compliance with the IRBs. The data presented herein represent analysis of 100 singleton newborns for whom we had complete data.

Table 1. Individual and household characteristics of the study sample.

\begin{tabular}{|c|c|c|}
\hline Variables & Categories & $\mathbf{N}(\%)$ \\
\hline \multirow{2}{*}{ Sex of newborn } & Male & $45(45 \%)$ \\
\hline & Female & $55(55 \%)$ \\
\hline \multirow{3}{*}{ Maternal age (years) (at newborn's birth) } & Age $<25$ & $21(21 \%)$ \\
\hline & $25 \leq$ age $<30$ & $34(34 \%)$ \\
\hline & Age $\geq 30$ & $45(45 \%)$ \\
\hline \multirow{2}{*}{ Maternal education (at newborn's birth) } & Up to high school & $30(30 \%)$ \\
\hline & Beyond high school & $70(70 \%)$ \\
\hline \multirow{2}{*}{ Previous pregnancies ${ }^{a}$} & Yes & $57(60 \%)$ \\
\hline & No & $38(40 \%)$ \\
\hline \multirow{7}{*}{ Assets owned by the Family } & $\mathrm{TV}^{\mathrm{b}}$ & $99(100 \%)$ \\
\hline & Refrigerator $^{\mathrm{c}}$ & $98(99 \%)$ \\
\hline & Freezer $^{\mathrm{d}}$ & $30(37 \%)$ \\
\hline & Living room set ${ }^{\mathrm{e}}$ & $80(86 \%)$ \\
\hline & Washing machine ${ }^{\mathrm{f}}$ & $75(81 \%)$ \\
\hline & Cars or other vehicle & $51(51 \%)$ \\
\hline & Cable/Satellite connection ${ }^{\mathrm{g}}$ & $72(74 \%)$ \\
\hline
\end{tabular}

a Previous pregnancies is missing for 5 mothers; ${ }^{b} \mathrm{TV}$ ownership is missing for 1 family;

c Refrigerator ownership is missing for 1 family; ${ }^{d}$ Freezer ownership is missing for 18 families;

${ }^{\mathrm{e}}$ Living room set ownership is missing for 7 families; ${ }^{\mathrm{f}}$ Washing machine ownership is missing for 7 families; ${ }^{\mathrm{g}}$ Cable/Satellite connection is missing for 3 families .

\subsection{Assessment of Lead, Mercury, Arsenic, Cadmium, Manganese, and Aluminum in Cord Blood}

In this study, whole cord blood samples were assayed for lead, mercury, arsenic, cadmium, manganese, and aluminum by the Trace Metals Lab at MDCH, a CDC certified lab for analysis of trace metals. MDCH followed a fully validated protocol for analyzing lead, mercury, arsenic, cadmium, manganese, and aluminum in cord blood samples with limits of detection (LoD) of 0.25 $\mu \mathrm{g} / \mathrm{dL}, 0.25 \mu \mathrm{g} / \mathrm{L}, 0.13 \mu \mathrm{g} / \mathrm{L}, 0.13 \mu \mathrm{g} / \mathrm{L}, 2.50 \mu \mathrm{g} / \mathrm{L}$, and $5.0 \mu \mathrm{g} / \mathrm{L}$, respectively. Ninety-nine percent of 
blood cadmium concentrations and $78 \%$ of blood arsenic concentrations were below the LoD. All samples were diluted and analyzed on a PerkinElmer Elan DRC II inductively-coupled plasma mass spectrometer (PerkinElmer, Waltham, MA, USA).

\subsection{Statistical Analysis}

The distributions of various characteristics of the study sample including demographic and socioeconomic status (SES) were examined. The distributions of various trace elements/metals in cord blood were also examined. If the distribution of any of the six trace elements/metals was skewed, the data were transformed using the natural logarithm (ln) in order to produce a distribution that better approximated a normal distribution. Descriptive statistics were used to characterize the distribution of the six trace elements/metals, including geometric means and standard deviations [58,59] for the ln-transformed variables (i.e., lead, mercury, and aluminum) and arithmetic means and standard deviations for all six of the trace elements/metals. Other descriptive measures are also provided, including median, interquartile range, and 25th, 75th, 90th, and 95th percentiles. For concentrations below the LoD, measurements were imputed by the midpoint between zero and the LoD for each trace element/metal.

General Linear Models (GLMs) were used to evaluate significant associations between blood trace element/metal concentrations and various socio-demographic characteristics of mothers and their newborns, including maternal age at the time of delivery, maternal education level, and SES as assessed by car ownership. In addition, possible associations of cord blood concentrations of lead, mercury, aluminum, and manganese with birth outcomes, including birth weight, crown-heel length, and head-circumference were assessed. Multivariable linear regression models were also fit to control for potential confounding by maternal education level and SES while investigating the associations between cord blood concentrations of the aforementioned trace elements/metals and birth outcomes. Since a majority of cord blood metal concentrations for arsenic and cadmium were below the LoD, the latter analyses did not include these two metals. All descriptive and inferential statistical analyses were conducted using SAS 9.3 [60]. All statistical tests were conducted at 5\% level of significance.

\section{Results}

The arithmetic mean (standard deviation (SD)) concentrations of cord blood lead, mercury, aluminum, and manganese in the sample of newborns in this study were $0.8(1.3 \mu \mathrm{g} / \mathrm{dL}), 4.4(2.4 \mu \mathrm{g} / \mathrm{L})$, $10.9(9.2 \mu \mathrm{g} / \mathrm{L})$, and $43.7(17.7 \mu \mathrm{g} / \mathrm{L})$, respectively. Because lead, mercury, and aluminum concentrations were not normally distributed, geometric mean (SD) blood concentrations of $0.6(1.8 \mu \mathrm{g} / \mathrm{L})$, $3.9(1.6 \mu \mathrm{g} / \mathrm{L})$, and $7.7(2.4 \mu \mathrm{g} / \mathrm{L})$ were also calculated. Notably, the percentage of cord blood samples with metal levels below the LoD was $2 \%$ for lead, $30 \%$ for aluminum, $99 \%$ for cadmium, and $78 \%$ for arsenic, and $0 \%$ for manganese and mercury. Additional information on the distributions of the six trace elements/heavy metals is displayed in Table 2. 
Table 2. Distribution of lead, mercury, arsenic, cadmium, manganese, and aluminum concentrations in umbilical cord blood in a sample of $n=100$ newborns from Jamaica.

\begin{tabular}{|c|c|c|c|c|c|c|c|c|c|}
\hline \multirow{2}{*}{ Variables } & \multirow{2}{*}{$\mathbf{N}$} & \multicolumn{2}{|c|}{ Mean (SD) } & \multirow{2}{*}{ Median } & \multirow{2}{*}{$\begin{array}{c}\text { Interquartile } \\
\text { Range }\end{array}$} & \multicolumn{4}{|c|}{ Percentiles } \\
\hline & & Arithmetic & Geometric & & & 25th & 75th & 90th & 95th \\
\hline Lead $(\mu \mathrm{g} / \mathrm{dL})$ & 100 & $0.8(1.3)$ & $0.6^{\mathrm{a}}(1.8)^{\mathrm{b}}$ & 0.6 & 0.3 & 0.4 & 0.8 & 1.2 & 1.7 \\
\hline Mercury $(\mu \mathrm{g} / \mathrm{L})$ & 100 & $4.4(2.4)$ & $3.9^{\mathrm{a}}(1.6)^{\mathrm{b}}$ & 4.0 & 2.4 & 2.8 & 5.2 & 7.0 & 7.6 \\
\hline Aluminum $(\mu \mathrm{g} / \mathrm{L})$ & 100 & $10.9(9.2)$ & $7.7^{\mathrm{a}}(2.4)^{\mathrm{b}}$ & 8.6 & 13.0 & 2.5 & 15.5 & 22.5 & 27.5 \\
\hline Manganese $(\mu \mathrm{g} / \mathrm{L})$ & 100 & $43.7(17.7)$ & $\mathrm{NR}^{\mathrm{e}}$ & 41.0 & 21.0 & 41.0 & 52.0 & 66.5 & 80.0 \\
\hline Arsenic $(\mu \mathrm{g} / \mathrm{L})^{\mathrm{c}}$ & 100 & $1.0(0.9)$ & $\mathrm{NR}^{\mathrm{e}}$ & 0.6 & 0.0 & 0.7 & 0.7 & 2.1 & 2.8 \\
\hline Cadmium $(\mu \mathrm{g} / \mathrm{L})^{\mathrm{d}}$ & 100 & $0.07(0.01)$ & $\mathrm{NR}^{\mathrm{e}}$ & 0.07 & 0.00 & 0.07 & 0.07 & 0.07 & 0.07 \\
\hline \multicolumn{10}{|c|}{$\begin{array}{l}\text { a Mean lead, mercury, and aluminum indicates the geometric mean }=\text { Exp. [Mean (ln of metal } \\
\text { concentration)]; b SD of lead, mercury, and aluminum indicates the geometric standard deviation }=\text { Exp. } \\
\text { [standard deviation of (ln of metal concentration)]; }{ }^{\mathrm{c}} 78(78 \%) \text { samples were below the limit of detection for } \\
\text { arsenic; }{ }^{\mathrm{d}} 99(99 \%) \text { samples were below the limit of detection for cadmium. Also, for ease of understanding, } \\
\text { the descriptive statistics for this variable are provided with two decimal places; }{ }^{\mathrm{e}} \mathrm{NR}=\text { geometric mean and } \\
\text { standard deviation were not reported because ln-transformation was not applied to these variables. }\end{array}$} \\
\hline
\end{tabular}

The mean (SD) birth weight for Jamaican newborns in this sample was $3.1(0.6 \mathrm{~kg})$. The mean crown-heel length for the total sample was $46.7(5.0 \mathrm{~cm})$. Additionally, the mean head circumference of newborns was $33.5(2.9 \mathrm{~cm})$. The mean gestational age was 39.3 (5.9) weeks. Details about birth outcomes, stratified by the sex of the newborns, are presented in Table 3.

Table 3. Descriptive analysis of continuous birth outcome variables stratified by sex of newborn.

\begin{tabular}{|c|c|c|c|c|c|c|c|c|}
\hline \multirow{2}{*}{$\begin{array}{c}\text { Birth Outcome } \\
\text { Variables } \\
\end{array}$} & \multicolumn{3}{|c|}{$\mathbf{N}$} & \multicolumn{3}{|c|}{ Mean (SD) } & \multirow{2}{*}{$\begin{array}{c}\text { Median } \\
\text { Total } \\
\end{array}$} & \multirow{2}{*}{$\begin{array}{l}\text { Interquartile } \\
\text { Range Total }\end{array}$} \\
\hline & Male & Female & Total & Male & Female & Total & & \\
\hline Head circumference $(\mathrm{cm})$ & 25 & 30 & 55 & $34.0(1.3)$ & $33.1(3.7)$ & $33.5(2.9)$ & 34.0 & 2.0 \\
\hline Crown-heel length $(\mathrm{cm})$ & 22 & 26 & 48 & $46.6(5.3)$ & $46.8(4.8)$ & $46.7(5.0)$ & 48.0 & 3.5 \\
\hline Birth weight (Kg) & 44 & 52 & 96 & $3.1(0.6)$ & $3.0(0.5)$ & $3.1(0.6)$ & 3.1 & 0.6 \\
\hline Apgar 1-minute scores & 34 & 43 & 77 & $7.9(1.7)$ & $8.4(1.0)$ & $8.2(1.4)$ & 9.0 & 1.0 \\
\hline Gestational age (weeks) & 35 & 38 & 73 & $38.0(2.2)$ & $40.5(7.8)$ & $39.3(5.9)$ & 39.0 & 2.0 \\
\hline
\end{tabular}

In univariable GLMs, the geometric mean blood aluminum concentration was higher for newborns whose mother did not have education beyond high school compared to those whose mother had attained this level $(12.2 v s .6 .4 \mu \mathrm{g} / \mathrm{L} ; p<0.01)$. In addition, newborns who belonged to a higher SES group (i.e., family owned a car) had a lower geometric mean blood aluminum concentration than newborns in families who did not own a car (6.4 vs. $9.3 \mu \mathrm{g} / \mathrm{L} ; p=0.03)$. Other associations between exposure to trace elements/metals and mothers' individual and household characteristics are presented in Table 4. Correlation analysis of cord blood metal concentrations with birth outcomes revealed that cord blood lead concentration was significantly correlated with birth head circumference $(p<0.01)$. 
Table 4. Univariable association of cord blood metal concentrations with mother's individual and household characteristics as potential confounding variables based on data from $n=100$ newborns.

\begin{tabular}{|c|c|c|c|c|c|c|c|c|c|c|}
\hline \multirow{2}{*}{ Variables } & \multirow{2}{*}{ Category } & \multirow{2}{*}{$\mathbf{N}$} & \multicolumn{2}{|l|}{ Lead } & \multicolumn{2}{|c|}{ Mercury } & \multicolumn{2}{|c|}{ Aluminum } & \multicolumn{2}{|c|}{ Manganese } \\
\hline & & & $\operatorname{Mean}^{a}(\mathrm{SD})^{\mathrm{b}}$ & $p$ & $\operatorname{Mean}^{a}(\mathrm{SD})^{\mathrm{b}}$ & $p$ & $\operatorname{Mean}^{a}\left(\right.$ SD) ${ }^{b}$ & $p$ & Mean (SD) & $p$ \\
\hline Maternal & $<30$ & 55 & $0.6(2.6)$ & \multirow{2}{*}{0.53} & $3.7(1.9)$ & \multirow{2}{*}{0.22} & $8.4(3.3)$ & \multirow{2}{*}{0.27} & $44.0(24.3)$ & \multirow{2}{*}{0.83} \\
\hline age (years) (at newborn's birth) & $\geq 30$ & 45 & $0.7(2.4)$ & & $4.2(2.1)$ & & $7.0(3.7)$ & & $43.2(26.9)$ & \\
\hline \multirow{2}{*}{$\begin{array}{l}\text { Maternal education } \\
\text { (at newborn's birth) }\end{array}$} & Up to high school & 30 & $0.6(3.2)$ & \multirow{2}{*}{0.88} & $3.7(2.4)$ & \multirow{2}{*}{0.35} & $12.2(4.5)$ & \multirow{2}{*}{$<0.01$} & $42.8(32.9)$ & \multirow{2}{*}{0.74} \\
\hline & Beyond high school & 70 & $0.6(2.1)$ & & $4.1(1.8)$ & & $6.4(2.7)$ & & $44.1(21.5)$ & \\
\hline \multirow{2}{*}{ Previous pregnancies $\mathbf{c}^{\mathbf{c}}$} & Yes & 57 & $0.6(2.4)$ & \multirow{2}{*}{0.51} & $3.9(1.9)$ & \multirow{2}{*}{0.55} & $8.0(3.2)$ & \multirow{2}{*}{0.81} & $43.0(24.2)$ & \multirow{2}{*}{0.56} \\
\hline & No & 38 & $0.6(2.8)$ & & $4.1(2.4)$ & & $7.7(4.1)$ & & $45.2(29.7)$ & \\
\hline \multirow{2}{*}{ Car ownership } & No & 49 & $0.6(2.5)$ & \multirow{2}{*}{0.73} & $3.8(2.0)$ & \multirow{2}{*}{0.30} & $9.3(3.4)$ & \multirow{2}{*}{0.03} & $46.0(25.5)$ & \multirow{2}{*}{0.21} \\
\hline & Yes & 51 & $0.6(2.4)$ & & $4.1(2.0)$ & & $6.4(3.3)$ & & $41.5(25.0)$ & \\
\hline
\end{tabular}

${ }^{\mathbf{a}}$ Mean lead, mercury, and aluminum indicates the geometric mean = Exp. [Mean (ln of metal concentration)] ${ }^{\mathbf{b}} \mathrm{SD}$ of lead, mercury, and aluminum indicates the geometric standard deviation $=$ Exp. [standard deviation of $(\ln \text { of metal concentration) }]^{\mathbf{c}}$ Previous pregnancies is missing for 5 mothers.

Table 5. Correlation coefficients (r) between cord blood metal concentrations and birth outcome variables.

\begin{tabular}{|c|c|c|c|c|c|c|c|c|c|}
\hline \multirow{2}{*}{ Birth Outcome Variables } & \multirow{2}{*}{$\mathbf{N}$} & \multicolumn{2}{|c|}{ Lead $^{\text {a }}$} & \multicolumn{2}{|c|}{ Mercury $^{a}$} & \multicolumn{2}{|c|}{ Aluminum a } & \multicolumn{2}{|c|}{ Manganese } \\
\hline & & $\mathbf{r}$ & $p$ & $\mathbf{r}$ & $p$ & $\mathbf{r}$ & $p$ & $\mathbf{r}$ & $p$ \\
\hline Birth weight (kg) & 96 & $<0.01$ & 0.96 & 0.13 & 0.20 & 0.01 & 0.89 & 0.09 & 0.40 \\
\hline Crown-heel length (cm) & 48 & 0.05 & 0.71 & -0.07 & 0.64 & 0.04 & 0.79 & -0.08 & 0.59 \\
\hline Head circumference $(\mathrm{cm})$ & 55 & -0.74 & $<0.01$ & -0.13 & 0.35 & -0.13 & 0.69 & -0.18 & 0.20 \\
\hline Apgar 1-minute scores & 77 & -0.07 & 0.55 & 0.01 & 0.93 & -0.10 & 0.40 & 0.01 & 0.93 \\
\hline Gestational age (weeks) & 73 & 0.02 & 0.88 & -0.03 & 0.78 & -0.17 & 0.14 & $<0.01$ & 0.96 \\
\hline
\end{tabular}

${ }^{a}$ For lead, mercury, and aluminum, ln-transformed cord blood metal concentrations were used. 
No other metal concentrations were found to be significantly correlated with birth outcomes. Correlation coefficients for these analyses are reported in Table 5. In multivariable GLMs, after controlling for potential cofounding variables that included maternal education level and SES, no significant association of mercury, aluminum, and manganese concentrations in cord blood with any of the aforementioned birth outcomes was found. However, cord blood lead concentration was inversely associated with head circumference (adjusted $p<0.01$ ). Moreover, though not statistically significant, the adjusted regression coefficients of head circumference with other cord blood metal concentrations were all negative. Adjusted slope coefficients and accompanying adjusted $p$-values for all multivariable models are shown in Table 6.

Table 6. Multivariable associations between cord blood metal concentrations and birth outcomes after controlling for SES and maternal education in the final multivariable linear regression models for birth outcomes.

\begin{tabular}{|c|c|c|c|c|c|c|c|c|c|}
\hline \multirow[b]{2}{*}{ Birth Outcome Variables } & \multirow[b]{2}{*}{$\mathbf{N}$} & \multicolumn{2}{|c|}{ Lead $^{\text {a }}$} & \multicolumn{2}{|c|}{ Mercury $^{a}$} & \multicolumn{2}{|c|}{ Aluminum ${ }^{a}$} & \multicolumn{2}{|c|}{ Manganese $^{\mathbf{b}}$} \\
\hline & & $\begin{array}{c}\text { Adjusted } \\
\text { Slope } \\
\text { Coefficient } \\
\end{array}$ & $p$ & $\begin{array}{c}\text { Adjusted } \\
\text { Slope } \\
\text { Coefficient } \\
\end{array}$ & $p$ & $\begin{array}{c}\text { Adjusted } \\
\text { Slope } \\
\text { Coefficient } \\
\end{array}$ & $p$ & $\begin{array}{c}\text { Adjusted } \\
\text { Slope } \\
\text { Coefficient } \\
\end{array}$ & $p$ \\
\hline Birth weight (kg) & 96 & 0.01 & 0.91 & 0.16 & 0.18 & 0.01 & 0.87 & 0.002 & 0.53 \\
\hline Crown-heel length $(\mathrm{cm})$ & 48 & 0.48 & 0.68 & -1.31 & 0.47 & -0.15 & 0.87 & -0.013 & 0.79 \\
\hline Head circumference $(\mathrm{cm})$ & 55 & -2.30 & $<0.01$ & -0.90 & 0.34 & -0.28 & 0.59 & -0.034 & 0.19 \\
\hline 1-minute Apgar score & 77 & -0.15 & 0.56 & $-0.011^{\mathrm{c}}$ & 0.98 & -0.14 & 0.50 & $<0.001^{\mathrm{d}}$ & 0.92 \\
\hline Gestational age (weeks) & 73 & 0.30 & 0.77 & -0.24 & 0.87 & -1.46 & 0.10 & -0.006 & 0.87 \\
\hline
\end{tabular}

${ }^{\mathbf{a}}$ For lead, mercury, and aluminum ln-transformed cord blood metal concentrations were used; ${ }^{\mathbf{b}}$ For ease of understanding, the adjusted slope coefficients for manganese are provided with three decimal places;

c For ease of understanding, the adjusted slope coefficient for 1-min Apgar score in relation to mercury is provided with three decimal places; ${ }^{\mathbf{d}}$ The actual value was 0.00097 .

\section{Discussion}

\subsection{Cord Blood Trace Element/Heavy Metal Concentrations in Jamaican Newborns}

In this paper, information was provided on blood trace element/metal concentrations in a sample of 100 newborn cord blood samples from 100 pregnant women in Jamaica, which could serve as a reference for the Jamaican population. In the following, findings for each of the six trace elements/metals investigated in this study are discussed.

\subsection{Lead Concentrations in Cord Blood}

The cord blood arithmetic mean lead concentrations reported in this study is $0.8(\mathrm{SD}=1.3 \mu \mathrm{g} / \mathrm{dL})$. Although there are no previous reports regarding levels of cord blood lead concentrations in Jamaican newborns, studies from several other countries have reported such levels in different populations. For example, a study from Belgium reported cord blood arithmetic mean lead concentration of $1.5 \mu \mathrm{g} / \mathrm{dL}$ [61]. Two separate studies from France reported cord blood arithmetic mean lead concentrations of $1.5 \mu \mathrm{g} / \mathrm{dL}[62,63]$ and $2.3 \mu \mathrm{g} / \mathrm{dL}$ [62,63]. A study from Canada reported cord blood arithmetic mean lead concentration of $2.8 \mu \mathrm{g} / \mathrm{dL}$ [64], and another study from Saudi Arabia reported 
cord blood arithmetic mean lead concentration of $2.5 \mu \mathrm{g} / \mathrm{dL}$ [65]. These data suggest that cord blood lead concentrations in Jamaican newborns are lower than that of the aforementioned developing and developed countries.

\subsection{Mercury Concentrations in Cord Blood}

The geometric mean cord blood total mercury concentration in the sample of newborns in this study was $3.9(\mathrm{SD}=1.6 \mu \mathrm{g} / \mathrm{L})$. About $20 \%(21 \%)$ of cord blood mercury concentrations exceeded $5.8 \mu \mathrm{g} / \mathrm{L}$, a level that has been shown to be associated with possible health effects in humans [66]. While these levels are higher than the geometric mean cord blood level reported in a community with high fish consumption in the Canadian Arctic (mean $=2.7 \mu \mathrm{g} / \mathrm{L}$ ) [64] and a sample from Saudi Arabia $($ mean $=2.6 \mu \mathrm{g} / \mathrm{L})$, these levels are lower than total mercury cord blood levels reported from Hawaii $($ mean $=5.2 \mu \mathrm{g} / \mathrm{L})[67]$ and Spain (geometric mean total mercury $=8.2 \mu \mathrm{g} / \mathrm{L}$ ) that are mainly attributed to maternal consumption of fish species high in mercury [68], while a study in an urban area in Spain only reported a geometric mean cord blood mercury concentration of $6.7 \mu \mathrm{g} / \mathrm{L}$ [69]. A previous report from our research in Jamaica also documented a significant association between seafood and fish consumption and mercury concentration in the blood of Jamaican children, aged 2-8 years [49]. Seafood, particularly due to the omega-3 polyunsaturated fatty acids in fish, is considered beneficial for human health [70]. While pregnant women are encouraged to eat fish during pregnancy because of its benefits, they are advised to limit its consumption due to contaminants such as methyl mercury in fish that may pose a hazard to the fetus [71]. Previous studies have reported conflicting findings regarding the association between total mercury concentrations in cord blood and birth weight. Some reported an inverse association between total mercury concentrations in cord blood and birth weight $[72,73]$ while others reported no such association [74,75]. Considering that fish consumption is an important source of exposure to mercury, which could have both beneficial and potentially harmful effects, it would be difficult to provide evidence-based guidelines for seafood consumption for use by the public without conducting a risk-benefit analysis [76,77]. However, the State of Pennsylvania in the US provided an advisory for fish consumption in 2012 that guides the public regarding frequency of fish consumption [78]. Australia and New Zealand have jointly published guidelines for seafood consumption [79].

\subsection{Cadmium Concentrations in Cord Blood}

Ninety nine percent (99\%) of cord blood samples had cadmium concentrations below the LoD of $0.13 \mu \mathrm{g} / \mathrm{L}$. Nearly similar, a study in the Canadian Artic reported only $26 \%$ of cord blood samples obtained had detectable levels of cadmium [64]. This is not surprising because it has been documented that the placenta acts as a barrier against the passage of this metal [23]. In addition, our previous report from Jamaica documented that about $66 \%$ of our sample of typically developing children (aged 2-8 years) had blood cadmium concentrations that were below the LoD [47]. Considering that cigarette smoke is a well-known source of human exposure to cadmium [64,80,81], and it has been previously reported that $10 \%$ of mothers were smokers [82], the low observed cadmium blood concentrations are not surprising. However, notably, a study of healthy, non-smoking women reported that cord blood cadmium concentrations were associated with a decrease in birth weight [83]. 


\subsection{Arsenic Concentrations in Cord Blood}

In our sample, $78 \%$ of cord blood samples had arsenic concentrations below the LoD of $0.13 \mu \mathrm{g} / \mathrm{L}$. However, a study that involved 460 newborns from Taiwan reported that no cord blood arsenic levels were below their LoD of $0.7 \mu \mathrm{g} / \mathrm{L}$ [84], while another study from China also indicated that none of the 2010 cord blood samples assessed were below their LoD of $0.41 \mu \mathrm{g} / \mathrm{L}$ [85]. Additionally, a study of

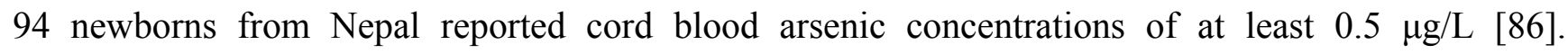
Our findings indicate that the cord blood arsenic concentrations in Jamaican newborns are much lower than those in other developing countries such as Taiwan and China.

\subsection{Manganese Concentrations in Cord Blood}

The cord blood manganese concentrations reported in this study (i.e., arithmetic mean $=43.7 \mu \mathrm{g} / \mathrm{L}$ ) are slightly higher than those observed in newborns from some parts of the developed world, including Paris, France (geometric mean $=38.5 \mu \mathrm{g} / \mathrm{L}$ ) [87], other metropolitan cities in France (arithmetic mean $=31.2 \mu \mathrm{g} / \mathrm{L}$ ) [62], and Canada (arithmetic mean $=34.4 \mu \mathrm{g} / \mathrm{L}$ ) [88]. However, the cord blood manganese concentrations from our Jamaican sample are comparable to those of the US (arithmetic mean $=44.0 \mu \mathrm{g} / \mathrm{L}$ and $42.0 \mu \mathrm{g} / \mathrm{L}$ from two different studies) [37,89]. Additionally, a study from Tehran, Iran, reported cord blood concentrations of $44.7 \mu \mathrm{g} / \mathrm{L}$ and $38.2 \mu \mathrm{g} / \mathrm{L}$ in newborns with intrauterine growth restriction and appropriate growth while also demonstrating greater manganese concentrations for smaller newborns [90]. However, mean cord blood manganese concentrations of our Jamaican sample are lower than those of a sample of newborns from Taiwan who had a mean cord blood manganese concentration of $52.8 \mu \mathrm{g} / \mathrm{L}$ [84]. The mean blood manganese concentration of typically developing children (aged 2-8 years) in Jamaica has been reported in our previous results as lower than that of other developing countries, but comparable to that of children in more developed countries, including the US and Australia [48]. Similar to our results, a study from Shanghai, China, showed no significant relationship between cord blood serum manganese concentrations and gestational age or birth weight [91]. Another study from the US also did not find a statistically significant association between cord blood manganese concentrations and birth weight [37]. Although neurobehavioral development of infants was not assessed in our study, it is important to note that the study in China found that cord blood serum manganese concentrations were associated with poor neurodevelopment in neonates [91].

\subsection{Aluminum Concentrations in Cord Blood}

The arithmetic mean cord blood aluminum concentration in this study was $10.9(\mathrm{SD}=9.2 \mu \mathrm{g} / \mathrm{L})$ and is higher than that (arithmetic mean $8.5 \mu \mathrm{g} / \mathrm{L}=0.04 \mu \mathrm{mol} / \mathrm{L}$ ) reported in newborns from Rzeszów, Poland [92]. Previous studies have shown that there is no safe level for aluminum [93,94]. Furthermore, the soil of Jamaica contains several trace elements and heavy metals, including aluminum [38,44]. As an exporter of bauxite, Jamaica has important sources of exposure to aluminum $[40,94,95]$, which supports our findings reported here. 


\subsection{Role of Cord Blood Metal Concentrations in Birth Outcomes}

In this study, possible associations of umbilical cord blood concentrations of lead, mercury, manganese, and aluminum with several birth outcomes that included birth weight, crown-heel length, and head circumference were also investigated. Consistent with univariable analyses, after controlling for potential cofounding variables that included maternal education level and SES, in our multivariable analysis, cord blood lead concentration was significantly associated with head circumference (adjusted $p<0.01$ ). However, a significant association of mercury, aluminum, and manganese concentrations in cord blood with any of the aforementioned birth outcomes was not found. Other studies, have reported associations of cord blood lead levels with birth outcomes such as birth weight $[14,24,36,83,92,96]$, and head circumference [15-17]. However, investigations evaluating the possible effects of in utero exposure to mercury [97,98] and manganese [37,91] on fetal growth have reported conflicting findings. Specifically, some reported an inverse association between cord blood mercury and fetal growth [99,100] or Apgar scores [101]. Other studies including our findings in this report did not show any significant associations between cord blood mercury and the aforementioned birth outcomes [98,102]. Some reports have attributed this conflict to maternal fish consumption habits, as many species contain beneficial nutrients that can compensate for the toxic effects of mercury [99]. Since we did not have dietary information from mothers, potential confounding of the results observed in our study by type of fish consumed could not be evaluated. Overall, our findings do not support an association between total mercury in cord blood and birth outcomes. Although previous studies have reported that in utero exposure to cadmium may have detrimental effects on newborns' health $[24,25,103-106]$, in our study, such effects were not evaluated due to extremely low levels of exposure (i.e., $99 \%$ were below the $\mathrm{LoD}$ ).

\subsection{Role of Maternal Education and SES in Cord Blood Metal Concentrations}

In the process of identifying potential confounding variables, significant associations of maternal education level and socioeconomic status (measure by ownership of a car by the family) with cord blood aluminum concentrations were found. In the following, we discuss these auxiliary findings.

Our findings indicated higher geometric mean cord blood aluminum concentrations for newborns whose mothers did not have education beyond high school compared to those whose mothers had attained this level (12.2 vs. $6.4 \mu \mathrm{g} / \mathrm{L} ; p<0.01)$. Other studies have not reported significant associations between maternal education and cord blood heavy metal concentrations. For example, Amaya et al. (2013) investigated potentially associated maternal factors (such as maternal education) with prenatal exposure to arsenic, cadmium, mercury, manganese, and lead in a population-based mother-child cohort in Southern Spain and found gestational age and smoking during pregnancy were associated with placental cadmium concentrations, while no factors were significantly associated with mercury, manganese, or lead concentrations [107]. In contrast, a study from the UK reported that high education attainment was independently associated with higher blood lead levels in pregnant women [108]. In addition, our findings indicated that newborns who belonged to families who owned a car (i.e., higher SES) had a lower geometric mean cord blood aluminum concentration than newborns in families who did not own a car $(6.4 v$ s. $9.3 \mu \mathrm{g} / \mathrm{L} ; p=0.03)$. To our knowledge, no other studies have reported a 
significant association between socioeconomic status and cord blood aluminum concentrations, however, some studies reported that children with lower SES have higher exposures to many chemical contaminants [109]. For example, Ahamed et al. reported that children with the lowest SES status who lived in Lucknow, India had significantly higher blood lead concentrations compared with other SES levels $($ low $=12.0 \mu \mathrm{g} / \mathrm{dL}$, middle $=8.4 \mu \mathrm{g} / \mathrm{dL}$, and high $=5.8 \mu \mathrm{g} / \mathrm{dL})[110]$. In contrast, Rahbar et al. did not find a significant difference between the geometric mean blood lead concentration in Jamaican children from families who owned a car (i.e., higher SES) and those who did not (i.e., lower SES), $(p=0.24)[111]$.

\section{Limitations}

We acknowledge several limitations in this study. First, since some of the 100 mothers in this study were not part of the JA Kids study, information from the third trimester and delivery questionnaires were not complete. This resulted in missing information for some of the variables reported here. Additionally, maternal nutritional intake was not assessed, thus nutritional exposures to the metals examined here, which have previously been shown to be associated with blood concentrations of various metals $[45,47,49,71]$ could not be investigated or adjusted for. Finally, there is the possibility of residual confounding by other factors not completely controlled for by the variables included in the analyses.

\section{Conclusions}

This study is the first to report levels of lead, mercury, arsenic, cadmium, manganese, and aluminum in cord blood of Jamaican newborns that could serve as a reference for the Jamaican population. In addition, the association of these metals in cord blood with certain birth outcomes was investigated. Our results indicate that cord blood lead concentrations in Jamaican newborns are significantly associated with their head circumference, after controlling for maternal education level and SES (through ownership of a family car). Our results also replicate previously reported significant associations between cord blood lead concentrations and birth head circumference in other populations. However, no such associations for concentrations of any other of the five trace elements/metals with birth outcomes were found. In the process of identifying factors associated with cord blood metal concentrations, we found significantly higher geometric mean cord blood aluminum concentrations in newborns whose mothers had a lower level of formal education as well as those who were born to families with lower SES. Therefore, improving SES and educating mothers regarding sources of exposure to aluminum could potentially reduce levels of this toxin in Jamaican newborns.

\section{Acknowledgments}

This research is co-funded by the National Institute of Environmental Health Sciences (NIEHS) by a grant (R01ES022165) as well as the Eunice Kennedy Shriver National Institute of Child Health and Human Development (NICHD) and the National Institutes of Health Fogarty International Center (NIH-FIC) by a grant (R21HD057808) awarded to University of Texas Health Science Center at Houston. We also acknowledge the support provided by the Child Cohort Study (JA Kids Study), 
supported by a grant from Inter-American Development Bank (IDB) Project Number (ATN/JF-12312JA) awarded to the University of the West Indies, Mona Campus, in Jamaica. Moreover, we acknowledge the support provided by the Biostatistics/Epidemiology/Research Design (BERD) component of the Center for Clinical and Translational Sciences (CCTS) for this project. CCTS is mainly funded by the NIH Centers for Translational Science Award (NIH CTSA) grant (UL1 RR024148), awarded to University of Texas Health Science Center at Houston in 2006 by the National Center for Research Resources (NCRR) and its renewal (UL1 TR000371) by the National Center for Advancing Translational Sciences (NCATS). The content is solely the responsibility of the authors and does not necessarily represent the official views of the NICHD or the NIH-FIC or NIEHS or the NCRR or the IDB or the NCATS. Furthermore, we acknowledge contributions by Ms. Samantha Foote related to data entry into the REDCap database from Jamaica. Finally, we acknowledge contributions by colleagues in the Trace Metals Lab at MDCH for analyzing and storing the cord blood samples for assessments of metal concentrations, under a service contract.

\section{Author Contributions}

Mohammad H. Rahbar and Maureen Samms-Vaughan have made substantial contributions to conception and study design; Maureen Samms-Vaughan, Charlene Coore Desai, Sydonnie Shakespeare-Pellington, Jody-Ann Reece, and Renee Morgan contributed to acquisition of data; Manouchehr Hessabi, Aisha S. Dickerson, Charlene Coore Desai, Sydonnie ShakespearePellington, Jody-Ann Reece, Maureen Samms-Vaughan, and Mohammad H. Rahbar have made contributions to data quality assurance procedures; Mohammad H. Rahbar, Aisha S. Dickerson, and Manouchehr Hessabi conducted data analysis; Mohammad H. Rahbar, Aisha S. Dickerson, Manouchehr Hessabi, and Jan Bressler have contributed to interpretation of data; Mohammad H. Rahbar, Aisha S. Dickerson, and Manouchehr Hessabi, and Jan Bressler significantly contributed to drafting of the manuscript, and Mohammad H. Rahbar, Jan Bressler, Megan L. Grove, Katherine A. Loveland, Maureen Samms-Vaughan, and Eric Boerwinkle provided critical revision of the manuscript; All authors have read and approved the final version submitted for publication.

\section{Conflicts of Interest}

The authors declare no conflict of interest.

\section{References}

1. National Scientific Council on the Developing Child. Early Exposure to Toxic Substances Damages Brain Architecture, Working Paper No. 4.; Center on the Developing Child at Harvard University: Cambridge, MA, USA, 2006.

2. Johnston, J.E.; Valentiner, E.; Maxson, P.; Miranda, M.L.; Fry, R.C. Maternal cadmium levels during pregnancy associated with lower birth weight in infants in a North Carolina cohort. PLoS One 2014, doi:10.1371/journal.pone.0109661.

3. Julvez, J.; Grandjean, P. Neurodevelopmental toxicity risks due to occupational exposure to industrial chemicals during pregnancy. Ind. Health 2009, 47, 459-468. 
4. Pan, J.; Song, H.; Pan, X.C. Reproductive effects of occupational exposure to mercury on female workers in China: A meta-analysis. Zhonghua Liu Xing Bing Xue Za Zhi 2007, 28, 1215-1218. (In Chinese)

5. Bose-O'Reilly, S.; McCarty, K.M.; Steckling, N.; Lettmeier, B. Mercury exposure and children's health. Curr. Probl. Pediatr. Adolesc. Health Care 2010, 40, 186-215.

6. Nadeau, K.C.; Li, Z.; Farzan, S.; Koestler, D.; Robbins, D.; Fei, D.L.; Malipatlolla, M.; Maecker, H.; Enelow, R.; Korrick, S.; et al. In utero arsenic exposure and fetal immune repertoire in a US pregnancy cohort. Clin. Immunol. 2014, 155, 188-197.

7. Rahman, A.; Vahter, M.; Ekstrom, E.C.; Rahman, M.; Golam Mustafa, A.H.; Wahed, M.A.; Yunus, M.; Persson, L.A. Association of arsenic exposure during pregnancy with fetal loss and infant death: A cohort study in Bangladesh. Am. J. Epidemiol. 2007, 165, 1389-1396.

8. Benett, R.W.; Persaud, T.V.; Moore, K.L. Experimental studies on the effects of aluminum on pregnancy and fetal development. Anat. Anz. 1975, 138, 365-378.

9. Domingo, J.L.; Gomez, M.; Colomina, M.T. Risks of aluminium exposure during pregnancy. Contrib. Sci. 2000, 1, 479-487.

10. Agency for Toxic Substances and Disease Registry (ATSDR). Toxicological Profile for Arsenic; Agency for Toxic Substances and Disease Registry: Atlanta, GA, USA, 2007.

11. U.S. Environmental Protection Agency (EPA). Implementation Guidance for the Arsenic Rule-Drinking Water Regulations for Arsenic and Clarifications to Compliance and New Source Contaminants Monitoring; U.S. Environmental Protection Agency: Washington, DC, USA, 2002.

12. Bellinger, D.C. Very low lead exposures and children's neurodevelopment. Curr. Opin. Pediatr. 2008, 20, 172-177.

13. Ha, M.; Kwon, H.J.; Lim, M.H.; Jee, Y.K.; Hong, Y.C.; Leem, J.H.; Sakong, J.; Bae, J.M.; Hong, S.J.; Roh, Y.M.; et al. Low blood levels of lead and mercury and symptoms of attention deficit hyperactivity in children: A report of the children's health and environment research (CHEER). Neurotoxicology. 2009, 30, 31-36.

14. Bellinger, D.C. Teratogen update: Lead and pregnancy. Birth Defects Res. A Clin. Mol. Teratol. 2005, 73, 409-420.

15. Hernandez-Avila, M.; Peterson, K.E.; Gonzalez-Cossio, T.; Sanin, L.H.; Aro, A.; Schnaas, L.; Hu, H. Effect of maternal bone lead on length and head circumference of newborns and 1-month-old infants. Arch. Environ. Health 2002, 57, 482-488.

16. Osman, K.; Akesson, A.; Berglund, M.; Bremme, K.; Schutz, A.; Ask, K.; Vahter, M. Toxic and essential elements in placentas of Swedish women. Clin. Biochem. 2000, 33, 131-138.

17. Ballew, C.; Khan, L.K.; Kaufmann, R.; Mokdad, A.; Miller, D.T.; Gunter, E.W. Blood lead concentration and children's anthropometric dimensions in the Third National Health and Nutrition Examination Survey (NHANES III), 1988-1994. J. Pediatr. 1999, 134, 623-630.

18. Falcon, M.; Vinas, P.; Luna, A. Placental lead and outcome of pregnancy. Toxicology 2003, 185, 59-66.

19. Torres-Sanchez, L.E.; Berkowitz, G.; Lopez-Carrillo, L.; Torres-Arreola, L.; Rios, C.; Lopez-Cervantes, M. Intrauterine lead exposure and preterm birth. Environ. Res. 1999, 81, 297-301. 
20. Roosli, M. Non-cancer effects of chemical agents on children's health. Prog. Biophys. Mol. Biol. 2011, 107, 315-322.

21. Sanders, T.; Liu, Y.; Buchner, V.; Tchounwou, P.B. Neurotoxic effects and biomarkers of lead exposure: A review. Rev. Environ. Health 2009, 24, 15-45.

22. Cohen, J.T.; Bellinger, D.C.; Shaywitz, B.A. A quantitative analysis of prenatal methyl mercury exposure and cognitive development. Am. J. Prev. Med. 2005, 29, 353-365.

23. McAleer, M.F.; Tuan, R.S. Metallothionein overexpression in human trophoblastic cells protects against cadmium-induced apoptosis. Vitr. Mol. Toxicol. 2001, 14, 25-42.

24. Zhang, Y.L.; Zhao, Y.C.; Wang, J.X.; Zhu, H.D.; Liu, Q.F.; Fan, Y.G.; Wang, N.F.; Zhao, J.H.; Liu, H.S.; Ou-Yang, L.; et al. Effect of environmental exposure to cadmium on pregnancy outcome and fetal growth: A study on healthy pregnant women in China. J. Environ. Sci. Health Pt. A. 2004, 39, 2507-2515.

25. Nishijo, M.; Nakagawa, H.; Honda, R.; Tanebe, K.; Saito, S.; Teranishi, H.; Tawara, K. Effects of maternal exposure to cadmium on pregnancy outcome and breast milk. Occup. Environ. Med. 2002, 59, 394-396.

26. Tong, S.; von Schirnding, Y.E.; Prapamontol, T. Environmental lead exposure: A public health problem of global dimensions. Bull. World Health Organ. 2000, 78, 1068-1077.

27. Bjornberg, K.A.; Vahter, M.; Petersson-Grawe, K.; Glynn, A.; Cnattingius, S.; Darnerud, P.O.; Atuma, S.; Aune, M.; Becker, W.; Berglund, M. Methyl mercury and inorganic mercury in Swedish pregnant women and in cord blood: Influence of fish consumption. Environ. Health Perspect. 2003, 111, 637-641.

28. Dorea, J.G.; Barbosa, A.C. Maternal mercury transfer. Environ. Res. 2003, 93, 113-114.

29. Agency for Toxic Substances and Disease Registry (ATSDR). Toxicological Profile for Cadmium; Agency for Toxic Substances and Disease Registry: Atlanta, GA, USA, 2012.

30. Pan, J.; Plant, J.A.; Voulvoulis, N.; Oates, C.J.; Ihlenfeld, C. Cadmium levels in Europe: Implications for human health. Environ. Geochem. Health 2010, 32, 1-12.

31. Sanchez-Martin, M.J.; Sanchez-Camazano, M.; Lorenzo, L.F. Cadmium and lead contents in suburban and urban soils from two medium-sized cities of Spain: Influence of traffic intensity. Bull. Environ. Contam. Toxicol. 2000, 64, 250-257.

32. Satarug, S.; Garrett, S.H.; Sens, M.A.; Sens, D.A. Cadmium, environmental exposure, and health outcomes. Environ. Health Perspect. 2010, 118, 182-190.

33. Ebisu, K.; Bell, M.L. Airborne $\mathrm{PM}_{2.5}$ chemical components and low birth weight in the northeastern and mid-Atlantic regions of the United States. Environ. Health Perspect. 2012, 120, 1746-1752.

34. Bell, M.L.; Belanger, K.; Ebisu, K.; Gent, J.F.; Lee, H.J.; Koutrakis, P.; Leaderer, B.P. Prenatal exposure to fine particulate matter and birth weight: Variations by particulate constituents and sources. Epidemiology 2010, 21, 884-891.

35. Shi, X.; Ayotte, J.D.; Onda, A.; Miller, S.; Rees, J.; Gilbert-Diamond, D.; Onega, T.; Gui, J.; Karagas, M.; Moeschler, J. Geospatial association between adverse birth outcomes and arsenic in groundwater in New Hampshire, USA. Environ. Geochem. Health 2015, 37, 331-351.

36. Wood, R.J. Manganese and birth outcome. Nutr. Rev. 2009, 67, 416-420. 
37. Zota, A.R.; Ettinger, A.S.; Bouchard, M.; Amarasiriwardena, C.J.; Schwartz, J.; Hu, H.; Wright, R.O. Maternal blood manganese levels and infant birth weight. Epidemiology 2009, 20, $367-373$.

38. Lalor, G.C. Geochemical mapping in Jamaica. Environ. Geochem. Health 1996, 18, 89-97.

39. Anglin-Brown, B.; Armour-Brown, A.; Lalor, G.C.; Preston, J.; Vutchkov, M.K. Lead in a residential environment in Jamaica. Environ. Geochem. Health 1996, 18, 129-133.

40. Authier-Martin, M.; Forte, G.; Ostap, S.; See, J. The mineralogy of bauxite for producing smelter-grade alumina. JOM 2001, 53, 36-40.

41. Lalor, G.C. Review of cadmium transfers from soil to humans and its health effects in the Jamaican environment. Sci. Total Environ. 2008, 400, 162-172.

42. Wright, P.; Rattray, R.; Lalor, G.; Hanson, R. Minimal health impact from exposure to dietsourced cadmium on a population in central Jamaica. Environ. Geochem. Health 2010, 32, 567581.

43. Wright, V.; Jones, S.; Omoruyi, F.O. Effect of bauxite mineralized soil on residual metal levels in some post harvest food crops in Jamaica. Bull. Environ. Contam. Toxicol. 2012, 89, 824-830.

44. Howe, A.; Fung, L.H.; Lalor, G.; Rattray, R.; Vutchkov, M. Elemental composition of Jamaican foods 1: A survey of five food crop categories. Environ. Geochem. Health 2005, 27, 19-30.

45. Rahbar, M.H.; Samms-Vaughan, M.; Ardjomand-Hessabi, M.; Loveland, K.A.; Dickerson, A.S.; Chen, Z.; Bressler, J.; Shakespeare-Pellington, S.; Grove, M.L.; Bloom, K.; et al. The role of drinking water sources, consumption of vegetables and seafood in relation to blood arsenic concentrations of Jamaican children with and without Autism Spectrum Disorders. Sci Total Environ. 2012, 433C, 362-370.

46. Agency for Toxic Substances and Disease Registry (ATSDR). ToxGuide ${ }^{T M}$ for Arsenic; Agency for Toxic Substances and Disease Registry: Atlanta, GA, USA, 2007.

47. Rahbar, M.H.; Samms-Vaughan, M.; Dickerson, A.S.; Loveland, K.A.; Ardjomand-Hessabi, M.; Bressler, J.; Lee, M.; Shakespeare-Pellington, S.; Grove, M.L.; Pearson, D.A.; et al. Role of fruits, grains, and seafood consumption in blood cadmium concentrations of Jamaican children with and without Autism Spectrum Disorder. Res. Autism Spectr. Disord. 2014, 8, 1134-1145.

48. Rahbar, M.H.; Samms-Vaughan, M.; Dickerson, A.S.; Loveland, K.A.; Ardjomand-Hessabi, M.; Bressler, J.; Shakespeare-Pellington, S.; Grove, M.L.; Pearson, D.A.; Boerwinkle, E. Blood manganese concentrations in Jamaican children with and without autism spectrum disorders. Environ. Health 2014, doi:10.1186/1476-069X-13-69.

49. Rahbar, M.H.; Samms-Vaughan, M.; Loveland, K.A.; Ardjomand-Hessabi, M.; Chen, Z.; Bressler, J.; Shakespeare-Pellington, S.; Grove, M.L.; Bloom, K.; Pearson, D.A.; et al. Seafood consumption and blood mercury concentrations in Jamaican children with and without autism spectrum disorders. Neurotox. Res. 2013, 23, 22-38.

50. The University of the West Indies. Jamaican Birth Cohort (JA Kids) Study; The University of the West Indies: Kingston, Jamaica, 2010.

51. McCaw-Binns, A.; Ashley, D.; Samms-Vaughan, M. Impact of the Jamaican birth cohort study on maternal, child and adolescent health policy and practice. Paediatr. Perinat. Epidemiol. 2010, 24, 3-11. 
52. IDB Funds UWI Study On Parent, Child Well-Being. The Gleaner, 8 November 2010, Jamaica. Available online: http://jamaica-gleaner.com/gleaner/20101108/lead/lead6.html (accessed on 22 April 2015).

53. Samms-Vaughan, M. Risk Resilience Child Development-Results from Jamaican Birth Cohort Studies (JPMMS) and 2011 (JAKIDS); International Symposium on Cohort and Longitudinal Studies in Developing Context, UNICEF Office of Research: Innocenti, Florence, Italy, 2014.

54. Harris, P.A.; Taylor, R.; Thielke, R.; Payne, J.; Gonzalez, N.; Conde, J.G. Research electronic data capture (REDCap) - A metadata-driven methodology and workflow process for providing translational research informatics support. J. Biomed. Inform. 2009, 42, 377-381.

55. Jackson, L.W.; Howards, P.P.; Wactawski-Wende, J.; Schisterman, E.F. The association between cadmium, lead and mercury blood levels and reproductive hormones among healthy, premenopausal women. Hum. Reprod. 2011, 26, 2887-2895.

56. Centers for Disease Control and Prevention (CDC). NHANES Laboratory Procedures Manual; Centers for Disease Control and Prevention (CDC): Atlanta, GA, USA, 2011.

57. Centers for Disease Control and Prevention (CDC). NHANES MEC Laboratory Procedures Manual; Centers for Disease Control and Prevention (CDC): Atlanta, GA, USA, 2013.

58. Finlay, W.H. Particle Size Distribution. In The Mechanics of Inhaled Pharmaceutical Aerosols: An Introduction; Finlay, W.H., Ed.; Academic Press: San Diego, CA, USA,2001; pp. 3-10.

59. U.S. Environmental Protection Agency (EPA). Appendix A: How to Calculate the Geometric Standard Deviation from Blood Lead Data, If You Must. U.S; Environmental Protection Agency: Washington, DC, USA, 1994.

60. SAS Institute Inc. $S A S^{\circledR}$ 9.3; SAS Institute Inc.: Cary, NC, USA, 2011.

61. Koppen, G.; Den, H.E.; Nelen, V.; van De Mieroop, E.; Bruckers, L.; Bilau, M.; Keune, H.; van Larebeke, N.; Covaci, A.; van De Weghe, H.; et al. Organochlorine and heavy metals in newborns: Results from the Flemish Environment and Health Survey (FLEHS 2002-2006). Environ. Int. 2009, 35, 1015-1022.

62. Abdelouahab, N.; Huel, G.; Suvorov, A.; Foliguet, B.; Goua, V.; Debotte, G.; Sahuquillo, J.; Charles, M.A.; Takser, L. Monoamine oxidase activity in placenta in relation to manganese, cadmium, lead, and mercury at delivery. Neurotoxicol. Teratol. 2010, 32, 256-261.

63. Yazbeck, C.; Cheymol, J.; Dandres, A.M.; Barbery-Courcoux, A.L. Lead exposure in pregnant women and newborns: A screening update. Arch. Pediatr. 2007, 14, 15-19.

64. Butler Walker, J.; Houseman, J.; Seddon, L.; McMullen, E.; Tofflemire, K.; Mills, C.; Corriveau, A.; Weber, J.P.; LeBlanc, A.; Walker, M.; et al. Maternal and umbilical cord blood levels of mercury, lead, cadmium, and essential trace elements in Arctic Canada. Environ. Res. 2006, 100, 295-318.

65. Al-Saleh, I.; Shinwari, N.; Mashhour, A.; Mohamed, G.D.; Rabah, A. Heavy metals (lead, cadmium and mercury) in maternal, cord blood and placenta of healthy women. Int. J. Hyg. Environ. Health 2011, 214, 79-101.

66. U.S. Environmental Protection Agency (EPA). Organic Mercury, Toxicity and Exposure Assessment for Children's Health; U.S.Environmental Protection Agency: Washington, DC, USA, 2007. 
67. Soon, R.; Dye, T.D.; Ralston, N.V.; Berry, M.J.; Sauvage, L.M. Seafood consumption and umbilical cord blood mercury concentrations in a multiethnic maternal and child health cohort. BMC Pregnancy Childbirth 2014, doi:10.1186/1471-2393-14-209.

68. Ramon, R.; Murcia, M.; Aguinagalde, X.; Amurrio, A.; Llop, S.; Ibarluzea, J.; Lertxundi, A.; Alvarez-Pedrerol, M.; Casas, M.; Vioque, J.; et al. Prenatal mercury exposure in a multicenter cohort study in Spain. Environ. Int. 2011, 37, 597-604.

69. Garcia-Esquinas, E.; Perez-Gomez, B.; Fernandez-Navarro, P.; Fernandez, M.A.; de Paz, C.; Perez-Meixeira, A.M.; Gil, E.; Iriso, A.; Sanz, J.C.; Astray, J.; et al. Lead, mercury and cadmium in umbilical cord blood and its association with parental epidemiological variables and birth factors. BMC Public Health 2013, doi:10.1186/1471-2458-13-841.

70. Kris-Etherton, P.M.; Harris, W.S.; Appel, L.J. Fish consumption, fish oil, omega-3 fatty acids, and cardiovascular disease. Circulation 2002, 106, 2747-2757.

71. Xue, F.; Holzman, C.; Rahbar, M.H.; Trosko, K.; Fischer, L. Maternal fish consumption, mercury levels, and risk of preterm delivery. Environ. Health Perspect. 2007, 115, $42-47$.

72. Foldspang, A.; Hansen, J.C. Dietary intake of methylmercury as a correlate of gestational length and birth weight among newborns in Greenland. Am. J. Epidemiol. 1990, 132, 310-317.

73. Sikorski, R.; Paszkowski, T.; Szprengier-Juszkiewicz, T. Mercury in neonatal scalp hair. Sci. Total Environ. 1986, 57, 105-110.

74. Grandjean, P.; Bjerve, K.S.; Weihe, P.; Steuerwald, U. Birthweight in a fishing community: significance of essential fatty acids and marine food contaminants. Int. J. Epidemiol. 2001, 30, 1272-1278.

75. Lucas, M.; Dewailly, E.; Muckle, G.; Ayotte, P.; Bruneau, S.; Gingras, S.; Rhainds, M.; Holub, B.J. Gestational age and birth weight in relation to n-3 fatty acids among Inuit (Canada). Lipids 2004, 39, 617-626.

76. Mozaffarian, D. Fish, mercury, selenium and cardiovascular risk: Current evidence and unanswered questions. Int. J. Environ. Res. Public Health 2009, 6, 1894-1916.

77. Turyk, M.E.; Bhavsar, S.P.; Bowerman, W.; Boysen, E.; Clark, M.; Diamond, M.; Mergler, D.; Pantazopoulos, P.; Schantz, S.; Carpenter, D.O. Risks and benefits of consumption of great lakes fish. Environ. Health Perspect. 2012, 120, 11-18.

78. Pennsylvania Fish and Boat Commission. Commonwealth of Pennsylvania Public Health Advisory 2012 Fish Consumption; Pennsylvania Summary of Fishing Regulations and Laws: Harrisburg, PA, USA, 2012.

79. Food Standards Australia New Zealand. Mercury in Fish; Food Standards Australia New Zealand: Canberra, Australia, 2011.

80. Menai, M.; Heude, B.; Slama, R.; Forhan, A.; Sahuquillo, J.; Charles, M.A.; Yazbeck, C. Association between maternal blood cadmium during pregnancy and birth weight and the risk of fetal growth restriction: The EDEN mother-child cohort study. Reprod. Toxicol. 2012, 34, $622-627$.

81. Jarup, L.; Akesson, A. Current status of cadmium as an environmental health problem. Toxicol. Appl. Pharmacol. 2009, 238, 201-208. 
82. Walker, S.P.; Ewan-Whyte, C.; Chang, S.M.; Powell, C.A.; Fletcher, H.; McDonald, D.; Grantham-McGregor, S.M. Factors associated with size and proportionality at birth in term Jamaican infants. J. Health Popul. Nutr. 2003, 21, 117-126.

83. Salpietro, C.D.; Gangemi, S.; Minciullo, P.L.; Briuglia, S.; Merlino, M.V.; Stelitano, A.; Cristani, M.; Trombetta, D.; Saija, A. Cadmium concentration in maternal and cord blood and infant birth weight: A study on healthy non-smoking women. J. Perinat. Med. 2002, 30, 395399.

84. Lin, C.C.; Chen, Y.C.; Su, F.C.; Lin, C.M.; Liao, H.F.; Hwang, Y.H.; Hsieh, W.S.; Jeng, S.F.; $\mathrm{Su}$, Y.N.; Chen, P.C. In utero exposure to environmental lead and manganese and neurodevelopment at 2 years of age. Environ Res. 2013, 123, 52-57.

85. Jin, L.; Zhang, L.; Li, Z.; Liu, J.M.; Ye, R.; Ren, A. Placental concentrations of mercury, lead, cadmium, and arsenic and the risk of neural tube defects in a Chinese population. Reprod. Toxicol. 2013, 35, 25-31.

86. Parajuli, R.P.; Fujiwara, T.; Umezaki, M.; Watanabe, C. Association of cord blood levels of lead, arsenic, and zinc with neurodevelopmental indicators in newborns: A birth cohort study in Chitwan Valley, Nepal. Environ. Res. 2013, 121, 45-51.

87. Takser, L.; Mergler, D.; Hellier, G.; Sahuquillo, J.; Huel, G. Manganese, monoamine metabolite levels at birth, and child psychomotor development. Neurotoxicology 2003, 24, 667-674.

88. Takser, L.; Mergler, D.; de Grosbois, S.; Smargiassi, A.; Lafond, J. Blood manganese content at birth and cord serum prolactin levels. Neurotoxicol. Teratol. 2004, 26, 811-815.

89. Jones, E.A.; Wright, J.M.; Rice, G.; Buckley, B.T.; Magsumbol, M.S.; Barr, D.B.; Williams, B.L. Metal exposures in an inner-city neonatal population. Environ. Int. 2010, 36, 649-654.

90. Vigeh, M.; Yokoyama, K.; Ramezanzadeh, F.; Dahaghin, M.; Fakhriazad, E.; Seyedaghamiri, Z.; Araki, S. Blood manganese concentrations and intrauterine growth restriction. Reprod. Toxicol. 2008, 25, 219-223.

91. Yu, X.D.; Zhang, J.; Yan, C.H.; Shen, X.M. Prenatal exposure to manganese at environment relevant level and neonatal neurobehavioral development. Environ. Res. 2014, 133, 232-238.

92. Zych, B.; Sztanke, M.; Kulesza-Bronczyk, B.; Lewandowski, B.; Sztanke, K.; Pasternak, K. The analysis of selected microelements in neonatal umbilical cord blood. J. Elementol. 2013, 18, 495-506.

93. Seneff, S.; Davidson, R.M.; Liu, J. Empirical data confirm autism symptoms related to aluminum and acetaminophen exposure. Entropy 2012, 14, 2227-2253.

94. Agency for Toxic Substances and Disease Registry (ATSDR). Toxicological Profile for Aluminum; Agency for Toxic Substances and Disease Registry: Atlanta, GA, USA, 2008.

95. Lalor, G.C. Geochemical Atlas of Jamaica; Canoe Press of the University of the West Indies: Kingston, Jamaica, 1995.

96. Fei, D.L.; Koestler, D.C.; Li, Z.; Giambelli, C.; Sanchez-Mejias, A.; Gosse, J.A.; Marsit, C.J.; Karagas, M.R.; Robbins, D.J. Association between In Utero arsenic exposure, placental gene expression, and infant birth weight: A US birth cohort study. Environ. Health 2013, doi:10.1186/1476-069X-12-58. 
97. Gundacker, C.; Frohlich, S.; Graf-Rohrmeister, K.; Eibenberger, B.; Jessenig, V.; Gicic, D.; Prinz, S.; Wittmann, K.J.; Zeisler, H.; Vallant, B.; et al. Perinatal lead and mercury exposure in Austria. Sci. Total Environ. 2010, 408, 5744-5749.

98. King, E.; Shih, G.; Ratnapradipa, D.; Quilliam, D.N.; Morton, J.; Magee, S.R. Mercury, lead, and cadmium in umbilical cord blood. J. Environ. Health 2013, 75, 38-43.

99. Ramon, R.; Ballester, F.; Aguinagalde, X.; Amurrio, A.; Vioque, J.; Lacasana, M.; Rebagliato, M.; Murcia, M.; Iniguez, C. Fish consumption during pregnancy, prenatal mercury exposure, and anthropometric measures at birth in a prospective mother-infant cohort study in Spain. Am. J. Clin. Nutr. 2009, 90, 1047-1055.

100. Oken, E.; Kleinman, K.P.; Olsen, S.F.; Rich-Edwards, J.W.; Gillman, M.W. Associations of seafood and elongated n-3 fatty acid intake with fetal growth and length of gestation: Results from a US pregnancy cohort. Am. J. Epidemiol. 2004, 160, 774-783.

101. Al-Saleh, I.; Shinwari, N.; Mashhour, A.; Rabah, A. Birth outcome measures and maternal exposure to heavy metals (lead, cadmium and mercury) in Saudi Arabian population. Int. J. Hyg. Environ. Health 2014, 217, 205-218.

102. Lederman, S.A.; Jones, R.L.; Caldwell, K.L.; Rauh, V.; Sheets, S.E.; Tang, D.; Viswanathan, S.; Becker, M.; Stein, J.L.; Wang, R.Y.; et al. Relation between cord blood mercury levels and early child development in a World Trade Center cohort. Environ. Health Perspect. 2008, 116, 1085-1091.

103. Lin, C.M.; Doyle, P.; Wang, D.; Hwang, Y.H.; Chen, P.C. Does prenatal cadmium exposure affect fetal and child growth? Occup. Environ. Med. 2011, 68, 641-646.

104. Ronco, A.M.; Arguello, G.; Suazo, M.; Llanos, M.N. Increased levels of metallothionein in placenta of smokers. Toxicology 2005, 208, 133-139.

105. Stasenko, S.; Bradford, E.M.; Piasek, M.; Henson, M.C.; Varnai, V.M.; Jurasovic, J.; Kusec, V. Metals in human placenta: Focus on the effects of cadmium on steroid hormones and leptin. J. Appl. Toxicol. 2010, 30, 242-253.

106. Kippler, M.; Hoque, A.M.; Raqib, R.; Ohrvik, H.; Ekstrom, E.C.; Vahter, M. Accumulation of cadmium in human placenta interacts with the transport of micronutrients to the fetus. Toxicol. Lett. 2010, 192, 162-168.

107. Amaya, E.; Gil, F.; Freire, C.; Olmedo, P.; Fernandez-Rodriguez, M.; Fernandez, M.F.; Olea, N. Placental concentrations of heavy metals in a mother-child cohort. Environ. Res. 2013, 120, 63-70.

108. Taylor, C.M.; Golding, J.; Hibbeln, J.; Emond, A.M. Environmental factors predicting blood lead levels in pregnant women in the UK: The ALSPAC study. PLoS One 2013, doi:10.1371/journal.pone.0072371.

109. Naess, O.; Piro, F.N.; Nafstad, P.; Smith, G.D.; Leyland, A.H. Air pollution, social deprivation, and mortality: A multilevel cohort study. Epidemiology 2007, 18, 686-694.

110. Ahamed, M.; Verma, S.; Kumar, A.; Siddiqui, M.K. Blood lead levels in children of Lucknow, India. Environ. Toxicol. 2010, 25, 48-54. 
111. Rahbar, M.H.; Samms-Vaughan, M.; Dickerson, A.S.; Loveland, K.A.; Ardjomand-Hessabi, M.; Bressler, J.; Shakespeare-Pellington, S.; Grove, M.L.; Boerwinkle, E. Factors associated with blood lead concentrations of children in Jamaica. J. Environ. Sci. Health Pt. A 2015, 50, 529-539.

(C) 2015 by the authors; licensee MDPI, Basel, Switzerland. This article is an open access article distributed under the terms and conditions of the Creative Commons Attribution license (http://creativecommons.org/licenses/by/4.0/). 